\title{
Resident uncertainty in clinical decision making and impact on patient care: a qualitative study
}

\author{
J M Farnan, ${ }^{1}$ J K Johnson, ${ }^{1}$ D 0 Meltzer, ${ }^{1,2}$ H J Humphrey, ${ }^{3}$ V M Arora ${ }^{1,3}$
}

${ }^{1}$ Section of Hospital Medicine, Department of Medicine, University of Chicago, Chicago, Illinois, USA; ${ }^{2}$ Department of Economics and Harris School of Public Policy, University of Chicago, Chicago, Illinois, USA ${ }^{3}$ Pritzker School of Medicine, University of Chicago, Chicago, Illinois, USA

Correspondence to:

Dr J M Farnan, University of Chicago, 5841 South Maryland Avenue, MC 2007, AMB B226A, Chicago, Illinois, USA; jfarnan@ medicine.bsd.uchicago.edu

Accepted 12 November 2007

\begin{abstract}
Background: Little is known regarding how internal medicine residents manage uncertainty during decision making and subsequent effects on patient care. The aims of this study were to describe types of uncertainty faced by residents, strategies employed to manage uncertainty and effects on patient care.
\end{abstract}

Methods: Using critical incident technique, residents were asked to recall important clinical decisions during a recent call night, with probes to identify decisions made during uncertainty. They were also asked to report who they approached for advice. Three authors independently coded transcripts using the constant comparative method.

Results: The 42/50 (84\%) interviewed residents reported 18 discrete critical incidents. Six categories emerged and mapped to the domains of the Beresford Model of Clinical Uncertainty: technical uncertainty (procedural skills, knowledge of indications); conceptual uncertainty (care transitions, diagnostic decision making and management conflict) and personal uncertainty (goals of care). In managing uncertainty, residents report a "hierarchy of assistance", using colleagues and literature for initial management, followed by senior residents, specialty fellows and, finally, the attending physician. Barriers to seeking the attending physician's input included the existence of a defined hierarchy for assistance and fears of losing autonomy, revealing knowledge gaps, and "being a bother". For 12 of the 18 cases reported, patient care was compromised: delay in procedure or escalation of care $(n=8)$; procedural complications $(n=2)$; and cardiac arrest $(\mathrm{n}=2)$.

Conclusion: Resident uncertainty results in delays of indicated care and, in some cases, patient harm. Despite the presence of a supervisory figure, residents adhere to a hierarchy when seeking advice in clinical matters.

Although uncertainty plagues many disciplines, its effects are especially palpable in medical training. Medical students, whose training provides textual knowledge for disease, enter residency limited in their ability to apply this knowledge to abstract clinical situations ${ }^{1}$ or psychosocial aspects of care. ${ }^{2}$ As residents become more autonomous, unclear expectations of supervising doctors and the everexpanding medical literature can compound their uncertainty. ${ }^{3}$ The pressures of time and the learning environment established by attending physicians can contribute to residents' questions going unanswered. ${ }^{4}$ Previous literature has also illustrated resident discomfort in executing unsupervised procedures and uncertainty in managing post-procedure complications. ${ }^{5}$

In these vulnerable moments, performing procedures and transitioning care between providers, ${ }^{6}$ uncertainty poses a significant threat to patient safety. A conceptual framework has been proposed by Beresford for the types of clinical uncertainty, which includes conceptual uncertainty (the inability to apply abstract knowledge to concrete situations), technical uncertainty, the absence of scientific data or practical skill and personal uncertainty, or the lack of previous relationship with a patient and knowledge of their care wishes. ${ }^{1}$ Despite the presence of this framework, no study has formally characterised the types of resident uncertainty or corresponding effects on care. This study aims to describe critical incidents occurring as a result of resident uncertainty, the types of uncertainty that plague resident decision making and strategies adopted by residents to deal with their own uncertainty.

\section{METHODS}

\section{Inpatient care at the University of Chicago}

The general medicine service at the University of Chicago consists of four teams, each with an attending physician who has completed internal medicine residency training, one resident doctor, two interns and, at times, one fourth year medical student sub-intern. ${ }^{7}$ Each team is on call every fourth night, with a maximum of 10 patient admissions each night. The attending physicians ensure that they are available in the day time to house staff via numerical or text paging and, when no longer in the medical centre, often provide residents with contact information including home and mobile telephone numbers. A mandate from the Internal Medicine Residency Program Director in January 2006 stated that "all admitting resident physicians need to contact [their] attending at least once during the call night to inform the attending of patients admitted under their name" to ensure attending physicians were notified promptly of patients admitted to their service. Those individuals in hospital on any given night include a faculty hospitalist (covering non-teaching services); a senior medicine triage resident, the medicine resident on call and fellow residents on subspecialty services. Fellows are available via page for subspecialty directed questions.

\section{Data collection}

The Institutional Review Board approved this study. Between January and November 2006, all internal medicine residents at a single academic tertiary care institution were privately interviewed within 1 week of their last call night of the rotation. All interviews were performed by one investigator (JF) and discussions were audiotaped for clarity and transcribed for analysis. Verbal 
Table 1 Categories of uncertainty generated in the present study

\begin{tabular}{lll}
\hline $\begin{array}{l}\text { Beresford Model } \\
\text { domain (n) }\end{array}$ & Major category generated (n) & Sub-theme (n) \\
\hline Conceptual uncertainty (11) & Transitions of care (6) & $\begin{array}{l}\text { Escalation of care (5) } \\
\text { Discharge readiness (1) }\end{array}$ \\
& $\begin{array}{l}\text { Diagnostic decision making (4) } \\
\text { Management conflict (1) }\end{array}$ \\
Technical uncertainty (6) & $\begin{array}{l}\text { Procedural skill (5) } \\
\text { Knowledge of indications (1) }\end{array}$ \\
Personal uncertainty (2) & Goals of care (2) \\
\hline
\end{tabular}

consent was obtained from the residents before the interview. Names and any references made to individuals or patients were de-identified to render the interview anonymous. Interviews were conducted at the conclusion of the rotation to prevent influence on decision making behaviour. The critical incident technique was used to elicit patient care decisions made during times of clinical uncertainty. Residents were asked to recall two to three important clinical decisions during their most recent call night, with probes to identify decisions made during uncertainty. Initially used in the investigation of aviation accidents, this technique allows for the documentation of infrequently occurring events via the use of personal observation and experience. ${ }^{8}$ Residents were also asked whether they sought advice, and from whom, to resolve their uncertainty.

\section{Data analysis}

All de-identified, anonymous transcripts were reviewed by three investigators (JF, VA, JJ) and analysed using the constant comparative methods, with no a priori hypotheses to generate initial categories. ${ }^{9}$ These categories were subsequently mapped to the Beresford Model of Uncertainty. Atlas ti (ATLAS.ti Scientific Software Development Company, GmbH, Berlin, Germany) qualitative analysis software, was used to facilitate retrieving, coding and sorting the data. Three independent reviewers (JF, VA, JJ) applied the categorical scheme to all transcripts and reliability testing was performed via triangulation. Discrepancies between reviewers were resolved via discussion until consensus was achieved.

\section{RESULTS}

\section{Clinical uncertainty}

Between January and November of 2006, 42 of 50 (84\%; 47\% men, $53 \%$ women; $52 \%$ postgraduate year 2 and $45 \%$ postgraduate year 3) eligible residents were interviewed at the conclusion of the general medicine inpatient rotation. These residents identified 18 discrete incidents which occurred as a result of uncertainty in their clinical decision making. Six major categories of uncertainty emerged during qualitative analysis of these incidents and mapped to the domains of the Beresford Model of Clinical Uncertainty (table 1).

Within the domain of conceptual uncertainty, the major categories observed included uncertainty in decision making at times of transition of care, specifically the determination of whether patients required escalation of care (eg, transfer to the intensive care unit) or were prepared for discharge. Within the conceptual domain, residents expressed uncertainty deciding between diagnostic or therapeutic options and conflict between the resident and the attending physician's preferences for patient management.

Themes which mapped to the domain of technical uncertainty included uncertainty regarding procedural skill and performance and knowledge of indications for procedures. The uncertainty surrounding the performance of procedures included either technical apprehension or ability to perform the procedure and the immediacy with which the procedure was to be performed. Finally, uncertainty regarding patient wishes and goals of care mapped to the domain of personal uncertainty, in which the lack of a personal relationship with the patient, or a breach of trust in that relationship, led to difficulties with decision making.

Of the 18 critical incidents described by residents as times of decision-making uncertainty, 10 resulted in patient harm. Six patients experienced a delay in an indicated procedure or diagnostic test, two had procedural complications and two had cardiac arrest and subsequently died. Representative patient outcomes are outlined in table 2 along with their sources of uncertainty.

\section{Seeking advice}

When residents were asked who they sought advice from to resolve uncertainty, they described a definitive hierarchy of assistance, in which answers were sought from a step-wise chain of four types of individual with increasing seniority (table 3). Coded responses were not treated as mutually exclusive such that a single resident often identified multiple sources of advice, approached in a step-wise fashion. If a question remained unanswered, residents would pursue advice from a "higher" source.

Table 2 Example patient outcomes in cases of resident uncertainty in decision making

\begin{tabular}{lll}
\hline Domain & $\begin{array}{l}\text { Major category/ } \\
\text { sub-theme }\end{array}$ & Representative comment and patient presenting chief complaint \\
\hline $\begin{array}{l}\text { Conceptual } \\
\text { uncertainty }\end{array}$ & $\begin{array}{l}\text { Escalation of care } \\
\text { CC: Patient with potassium of 7.3: "it was a lesson ..., some of the stuff I mean if I am worried } \\
\text { about it I think I get caught up in like I don't want to bother the renal fellow and they said [the } \\
\text { patient] doesn't need dialysis and even if I think she does, I am the lowly resident so that was one } \\
\text { where ..., I should have just like bit the bullet and called because it sounds like they actually had } \\
\text { the [wrong] information ... everything was fine, she didn't like die or ... but I think she would have } \\
\text { benefited from dialysing earlier and I would have gotten some sleep" [R\#11] }\end{array}$
\end{tabular}

Technical Procedural skill CC: Patient with HIV/AIDS, fever, and mental status changes "the standard work up included an LP uncertainty and I felt like I couldn't get, I am not trained on how to do them and I just felt like let's do this Personal Goals of care uncertainty

\section{tomorrow ..."[R\#12]}

CC: Patient with severe chronic obstructive pulmonary disease transferred from medical intensive care unit to general medicine service "I discussed with a lot, with this particular patient's outpatient attending and the decision was made pretty quickly to make him comfort care and he actually died that day and I never actually talked with my [ward] attending about that patient until I talked with her later in the night and said that he had passed away and then the next day it was obvious that we had missed something on the chest $x$ ray" $[\mathrm{R} \# 8]$
Representative patient outcome

Patient did not require escalation of care; patient did not have an adverse event

Patient treated empirically with meningitis-appropriate doses of antibiotics*

Patient given comfort care after family discussion and died, secondary to an unrecognised procedural complication 
Table 3 The hierarchy of assistance sought by residents

\begin{tabular}{|c|c|c|c|}
\hline Domain (n) & Major category (n) & Sub-theme (n) & Representative comment \\
\hline \multirow[t]{5}{*}{$\begin{array}{l}\text { Sources of } \\
\text { advice (27) }\end{array}$} & Colleagues (13) & Peers (10) & $\begin{array}{l}\text { "if I have a question about something I will ask the residents around in the workroom because it is mostly on call when I } \\
\text { have these questions and um, I'll ask around with like round table type thing" [R\#22] }\end{array}$ \\
\hline & & Senior residents (3) & $\begin{array}{l}\text { "you know I would probably say MICU [medical ICU resident] is the main person that I would ask on call, the MROC } \\
\text { [senior triage resident] is the other person }[R \# 31]\end{array}$ \\
\hline & $\begin{array}{l}\text { Sub-specialty } \\
\text { fellow }(6)\end{array}$ & & $\begin{array}{l}\text { "sometimes I curbside the appropriate fellow, I think I do that quite a bit, I think I do that more than talking to the } \\
\text { attending" [R\#28] }\end{array}$ \\
\hline & Literature (6) & & "I do 'Up-to-Date' first ... then try to get a differential ... then come up with some thing"[R\#21] \\
\hline & $\begin{array}{l}\text { Attending physician } \\
\text { (2) }\end{array}$ & & $\begin{array}{l}\text { "So if I have something that is really pressing I would probably page my attending because you know he's my boss and } \\
\text { so I you know I would turn to him for advice unless its something, you know I would if it was difficult or pressing" } \\
\text { [R\#27] }\end{array}$ \\
\hline
\end{tabular}

Residents also described facilitators of immediate notification of the attending physician and barriers to seeking their input (fig 1; table 4). Barriers to seeking attending-level advice included: conflict with decision-making autonomy; fear of revealing gaps in knowledge; fear of repercussion; and adherence to the defined hierarchy of assistance. Despite these barriers, residents described scenarios which facilitated earlier involvement of the attending physician. These included the immediate need for escalation of care, having to choose from multiple diagnostic or therapeutic options, when the clinical experience of the attending physician would influence the decision.

\section{DISCUSSION}

This study suggests resident uncertainty can result in delays of indicated care and, in some cases, patient harm. Gerrity and colleagues have described extensively the stress and anxiety generated by doctors' clinical uncertainty, and it is these affective reactions to uncertainty which have the potential to result in patient harm. ${ }^{10}{ }^{11}$ Excessive ordering of tests and withholding information from patients are two examples of doctors' maladaptive responses to uncertainty with detrimental patient effects. ${ }^{12}$ It is important to consider the types of uncertainty encountered by residents and strategies to reduce them in the context of clinical care.

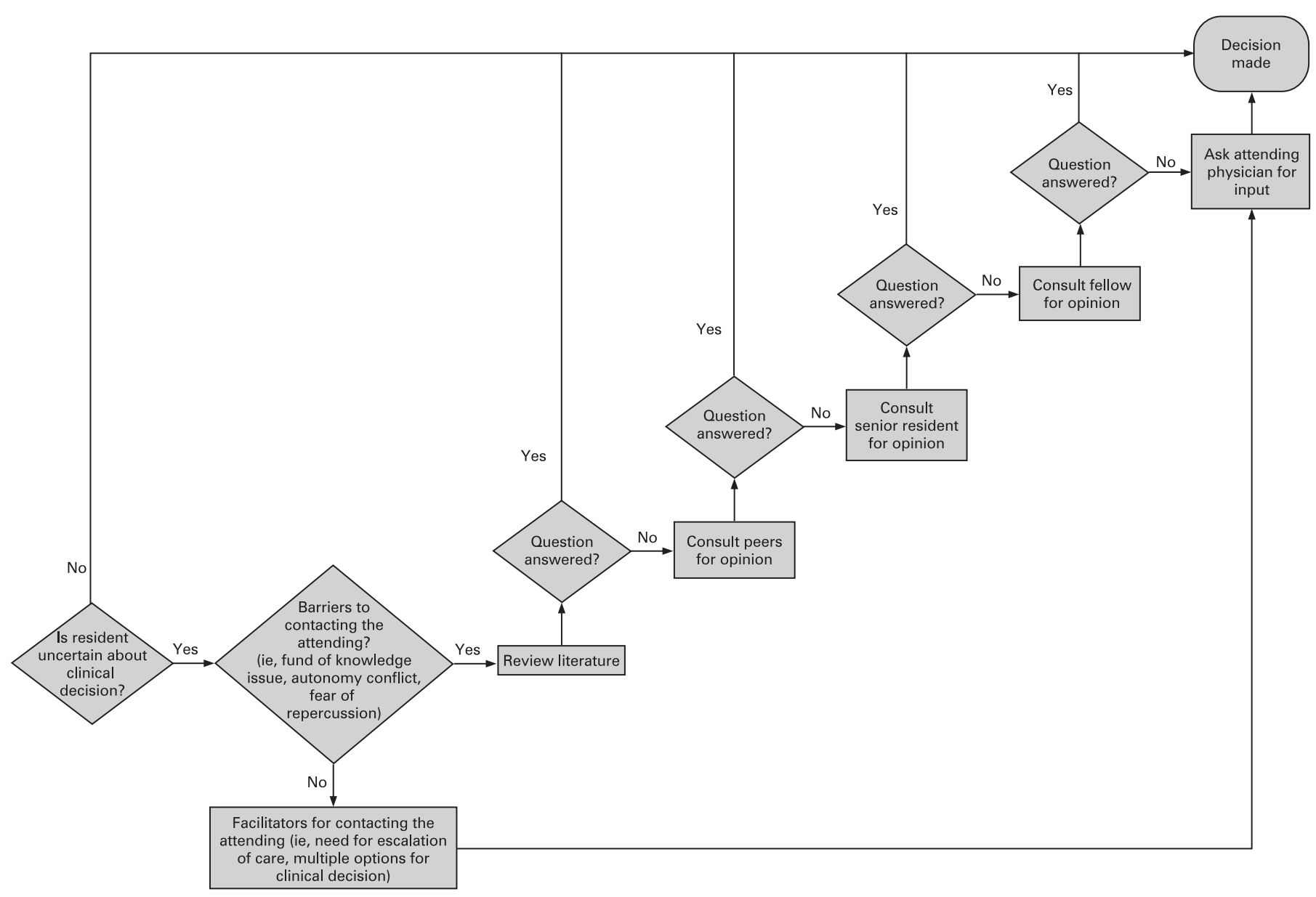

Figure 1 Clinical decision making as described by residents. 
Table 4 Facilitators of immediate notification of the attending physician and barriers to seeking attending input

\begin{tabular}{|c|c|c|}
\hline Domain (n) & Major categories (n) & Representative comments \\
\hline \multirow{4}{*}{$\begin{array}{l}\text { Barriers to seeking } \\
\text { attending physican's } \\
\text { advice (7) }\end{array}$} & $\begin{array}{l}\text { Conflict with decision making } \\
\text { autonomy (2) }\end{array}$ & $\begin{array}{l}\text { "it was a pain to kind of run by things with [the attending] ... because it would kind of influence things too much } \\
\text { and then you wouldn't get a chance to make up your own mind and figure it out." [R\#21] }\end{array}$ \\
\hline & $\begin{array}{l}\text { Fund of knowledge expectations } \\
\text { (2) }\end{array}$ & $\begin{array}{l}\text { "I would turn to [the attending] for advice unless it's something, I would if it was difficult or pressing, but I mean if } \\
\text { it's a question just something that I didn't know the answer to ..." }[R \# 27]\end{array}$ \\
\hline & $\begin{array}{l}\text { Existence of defined hierarchy } \\
\text { (2) }\end{array}$ & $\begin{array}{l}\text { "... between [the MICU resident or the MROC] or the other residents, I usually talk to them before I would make a } \\
\text { decision to go up the chain" [R\#38] }\end{array}$ \\
\hline & Fear of repercussion (1) & $\begin{array}{l}\text { 'I mean [the attending] said I could call him in the middle of the night if I needed anything but I am not going to do } \\
\text { that ... I am not going to wake him up ..." [R\#35] }\end{array}$ \\
\hline \multirow{3}{*}{$\begin{array}{l}\text { Facilitators to seeking } \\
\text { the attending } \\
\text { physician's advice (6) }\end{array}$} & Need for escalation of care (4) & $\begin{array}{l}\text { "it wasn't anything that critical it needed to be addressed that night, if I had been I would have been totally } \\
\text { comfortable calling my attending because she made it a point to know that that was fine in calling" [R\#39] }\end{array}$ \\
\hline & Options in decision making (1) & $\begin{array}{l}\text { "I feel like I can call the attendings if I have questions above my head or especially if there are a couple of options } \\
\text { of what to do on the question I always run it by the attending to make sure, even if its with a text page" [R\#37] }\end{array}$ \\
\hline & Clinical experience (1) & $\begin{array}{l}\text { "but if it were more like a clinical judgment thing and I hadn't had that situation then I would ask [the attending] } \\
\text {..."[R\#22] }\end{array}$ \\
\hline
\end{tabular}

The most commonly reported type of uncertainty, conceptual uncertainty, demonstrates a resident's inability to apply abstract criteria to a clinical scenario, in particular in the setting of the need for escalation of care. ${ }^{1}$ Such transitions, escalation of care or discharge, are when patients may be particularly vulnerable. ${ }^{6}$ Explicitly laying the groundwork with housestaff regarding supervision in such situations may alleviate some of this uncertainty. Recent work by colleagues from outside the USA highlights the importance of "responsive oversight" or supervision provided to housestaff triggered by "situation or trainee-specific cues". ${ }^{13}$ These cues include "reflecting on trainees' abilities" particularly in the settings of critical clinical decision making, scenarios often plagued by uncertainty. ${ }^{13}$ Previous work has illustrated that alternative curricula highlighting the impact of uncertainty in decision making can provide learners with insight into the process of their decisions. ${ }^{14}$ The implementation of a formalised decision making curriculum, using standardised patient care scenarios with clinical ambiguity, may provide a safe environment for residents to recognise and acquire skills to manage their uncertainty.

Resident procedural uncertainty has been documented previously, ${ }^{5}$ but here we describe the distal impact of such uncertainty, the delay or omission of clinically indicated procedures secondary to technical limitations or inadequate knowledge. In all of the incidents identified where a procedure was indicated, it was not performed by the team secondary to apprehension. The American Board of Internal Medicine (ABIM) procedural requirement for certification for internal medicine residency trainees has changed from actual demonstration of performance to the ability to "know, understand and explain" certain procedures. ${ }^{15}$ Our study demonstrates that internal medicine residents continue to be primarily responsible for performing indicated procedures in a safe and timely manner for hospitalised patients. Therefore, ensuring that residents can adequately perform procedures remains paramount to safe patient care. Simulation and other novel techniques may provide a safe environment for skill acquisition in these critical areas. $^{16}$

To address their uncertainty, residents describe an informal hierarchy of individuals to approach for advice. The hidden curriculum, the set of informal, institutional or cultural expectations placed upon trainees helps to maintain this hierarchy. ${ }^{17}$ The fear of being perceived as "weak" prevents residents from seeking advice when it is most needed. Unfortunately, these hierarchies, which have been described in surgical teams, also generate a delay in the delivery of indicated care and jeopardise patient safety. ${ }^{18}$ The reliance on colleagues, either resident peers or more senior subspecialty fellows may be fraught with error. The anecdotal advice of colleagues often differs greatly from the advice in evidence-based literature. ${ }^{19}$ Additional literature also demonstrates that, although no significant outcomes differences were appreciated, uncertainty has been shown to impact on doctors' searching processes in the attempt to answer clinical questions. ${ }^{20}$ These issues need to be a focus of continued education, for both faculty and residents, with improved direct supervision and policy changes requiring timely notification for all new admissions and improved utilisation of resources for sound clinical decision making.

There are several limitations to this study. First, it was conducted at one academic institution raising questions of generalisability. Despite institution-specific cultural effects, the general structure of teams comprising trainee and attending physicians is pervasive in both the USA and international academic medical centres. In addition, given the congruence with the qualitative data collected, the existing conceptual model described by Beresford and lack of previous work in this field, we are confident these findings will serve as a stimulus for future work. Expectation-led interviewer effects may influence data collection, such that the interviewer may have inadvertently influenced respondents to produce outcomes consistent with expectations. ${ }^{21}$ However, given the predominance of categories that emerged, this is less likely. Our findings are subject to hindsight bias due to retrospective analyses of the patient care incidents. ${ }^{22}$ This may overlook other factors which may have affected patient outcomes, such as workload and system factors. Because of this, our findings are certainly not definitive, but provide a preliminary view of the impact of resident uncertainty on the delivery of patient care.

\section{CONCLUSION}

Uncertainty in resident clinical decision making can result in delaying the delivery of indicated care, in some cases resulting in patient harm. Despite the presence of a supervisory figure, residents adhere to an hierarchy when seeking advice in clinical matters.

Acknowledgements: We thank M D'Arcy for his excellent research assistance.

Funding: This research was supported by the Department of Medicine at the University of Chicago.

Competing interests: None.

Ethics approval: The Institutional Review Board of the Biological Sciences Division of the University of Chicago approved this study. 


\section{REFERENCES}

1. Beresford EB. Uncertainty and the shaping of medical decisions. Hastings Cent Rep 1991:21:6-11.

2. Timmermans $\mathbf{S}$, Angell A. Evidence-based medicine, clinical uncertainty, and learning to doctor. J Health Soc Behav 2001;42:342-59.

3. Light D Jr. Uncertainty and control in professional training. J Health Soc Behav 1979;20:310-22.

4. Green ML, Ruff TR. Why do residents fail to answer their clinical questions? A qualitative study of barriers to practicing evidence-based medicine. Acad Med 2005;80:176-82.

5. Huang GC, Smith CC, Gorden CE, et al. Beyond the comfort zone: residents assess their comfort performing inpatient medical procedures. Am J Med 2006;119:e17-24.

6. Arora V, Johnson J, Lovinger D, et al. Communication failures in patient sign-out and suggestions for improvement: a critical incident analysis. Qual Saf Health Care 2005;14:401-7.

7. Arora V, Dunphy $\mathrm{C}$, Chang $\mathrm{VY}$, et al. The effects of on-duty napping on intern sleep time and fatigue. Ann Intern Med 2006;144:792-8.

8. Flanagan JC. The critical incident technique. Psychol Bull 1954;51:327-58.

9. Strauss A, Corbin J. Basics of qualitative research, 2nd edn. Thousand Oaks, CA: Sage Publications, 1998.

10. Gerrity MS, DeVellis RF, Earp JA. Physicians' reactions to uncertainty in patient care. A new measure and new insights. Med Care 1990:28:724-36.

11. Gerrity MS, Earp JA, DeVellis RF, et al. Uncertainty and professional work: perceptions of physicians in clinical practice. Am J Sociol 1992;97:1022-51.

12. Kassirer JP. Our stubborn quest for diagnostic certainty. A cause of excessive testing. N Engl J Med 1989;320:1489-91.
13. Kennedy TJ, Lingard L, Baker GR, et al. Clinical oversight: conceptualizing the relationship between supervision and safety. J Gen Intern Med 2007:22:1080-5.

14. Hall KH. Reviewing intuitive decision-making and uncertainty: the implications for medical education. Med Educ 2002;36:216-24.

15. American Board of Internal Medicine. Procedural requirements for internal medicine. http://www.abim.org/certification/policies/imss/im.aspx (accessed 25 May 2007).

16. Meier AH, Henry J, Marine R, et al. Implementation of a web- and simulation-based curriculum to ease the transition from medical school to surgical internship. Am J Surg 2005; 190:137-40.

17. Hundert EM, Hafferty F, Christakis D. Characteristics of the informal curriculum and trainees' ethical choices. Acad Med 1996;71:624-42.

18. Sexton JB, Thomas EJ, Helmreich RL. Error, stress, and teamwork in medicine and aviation: cross sectional surveys. BMJ 2000;320:745-9.

19. Schaafsma F, Verbeek J, Hulshof C. Caution required when relying on a colleague's advice; a comparison between professional advice and evidence from the literature. BMC Health Serv Res 2005;5:59.

20. McKibbon KA, Fridsma DB, Crowley RS. How primary care physicians' attitudes toward risk and uncertainty affect their use of electronic information resources. J Med Libr Assoc 2007;95:138-46, e49-50.

21. Holden JD. Hawthorne effects and research into professional practice. J Eval Clin Pract 2001;7:65-70.

22. Cook RI, Woods DD, Miller C. A tale of two stories: contrasting views on patient safety. National Health Care Safety Council of the National Patient Safety Foundation at the AMA, Chicago, Illinois, USA, 1997.

\section{Save your favourite articles and useful searches}

Use the "My folders" feature to save and organise articles you want to return to quickly-saving space on your hard drive. You can also save searches, which will save you time. You will only need to register once for this service, which can be used for this journal or all BMJ Journals, including the BMJ. 